\title{
Maternal factors associated with large for gestational age babies and its outcome when compared with those of appropriate for gestational age
}

\author{
Lopamudra B. John*, Reddi Rani P., Seetesh Ghose
}

Department of Obstetrics and Gynecology, Mahatma Gandhi Medical College and Research Institute, Pondicherry, India

Received: 07 June 2017

Accepted: 29 June 2017

*Correspondence:

Dr. Lopamudra B. John,

E-mail: drlopamdpondy@yahoo.com

Copyright: (c) the author(s), publisher and licensee Medip Academy. This is an open-access article distributed under the terms of the Creative Commons Attribution Non-Commercial License, which permits unrestricted non-commercial use, distribution, and reproduction in any medium, provided the original work is properly cited.

\begin{abstract}
Background: Large for gestational age (LGA) babies are known to have a higher incidence of birth trauma, difficult delivery and Caesarean sections. Knowledge about maternal factors associated with this can help in prediction and prevention of complications.

Methods: Maternal factors in 112 cases of LGA babies was studied along with its outcome and compared with an equal number of controls.

Results: $0.05 \%$ deliveries resulted in LGA babies. Age and parity were not significantly different in the two groups and so were the associated medical disorders of hypothyroidism and gestational hypertension. Significant association was found with post-dated pregnancies $(\mathrm{p}=0.04)$ and gestational diabetes mellitus $(\mathrm{p}=0.05)$. Also, higher number of primary Caesarean sections resulted in the case group.

Conclusions: Post dated pregnancies and gestational diabetes were maternal factors associated with LGA babies and higher number of primary Caesarean sections resulted in these cases.
\end{abstract}

Keywords: Large for gestational age, Maternal factors, Outcome

\section{INTRODUCTION}

Foetal macrosomia is a common obstetrical problem affecting $20 \%$ babies born at term. ${ }^{1}$ Conventionally babies with birth weight more than 90th percentile is considered to be large for gestational age and those between $5^{\text {th }}$ and $90^{\text {th }}$ percentile as appropriate for gestational age. The birth weight cut-off may be based on absolute birth weight or greater than a particular percentile for the babies of that gestational age. ${ }^{2}$ Large for gestational age babies can lead to complications during delivery like prolonged labour, shoulder dystocia, birth injuries, post-partum haemorrhage, increased need for caesarean sections for cephalopelvic disproportion, anaesthetic complications and thromboembolic events. ${ }^{3}$ Also neonatal adverse outcomes of hypoglycemia, hypomagnesemia and hyperbilirubinemia are more common in these babies. ${ }^{4}$ Antenatal detection of large for gestational age foetus will be helpful in anticipating these complications. This study is undertaken to determine the maternal factors associated with this condition so that the complications can be anticipated and managed in a better manner if not prevented.

\section{METHODS}

This study was conducted in a tertiary care center based on collection of retrospective data about large for gestational age (LGA) babies born over a period of one year. The inclusion criteria were singleton pregnancies which resulted in LGA babies over this period of time. All the mothers who delivered babies who were large for 
gestational age were categorized as the case group. The control group consisted of an equal number of women who delivered singleton babies over the same time period who were considered to be appropriate for gestational age. Large for gestational age was taken to be a birth weight cut-off of more than $90^{\text {th }}$ percentile for the gestational age.

Appropriate for gestational age was considered to be birth weights between $5^{\text {th }}$ and $90^{\text {th }}$ percentile for the gestational age.

The maternal factors associated with these pregnancies were recorded which were age, parity, gestational age at delivery, associated medical complications like gestational diabetes mellitus, gestational hypertension and hypothyroidism. Delivery outcomes studied were the mode of delivery, baby birth weight and need for neonatal intensive care. The above parameters in the case group were then compared with the control group and statistical analysis was done for the data.

\section{RESULTS}

A total number of 112 cases were recorded over a period of one year which constituted $0.05 \%$ of the deliveries and named as the case group. The control group consisted of equal number of patients who delivered AGA babies.

Table 1: Age distribution of mothers with LGA babies.

\begin{tabular}{lllcccc} 
Obs. & Sum & Mean(years) & Variance & Std Dev & $(95 \%$ CI mean) & Std Err \\
112 & 2973.00 & 26.54 & 13.28 & 3.64 & $25.86-27.23$ & 0.34 \\
\hline
\end{tabular}

Table 2: Order of pregnancy in the case group.

\begin{tabular}{|lll|}
\hline Gravida & $\mathbf{n}$ & $\%$ \\
\hline 1 & 40 & 35.7 \\
\hline 2 & 46 & 41.1 \\
\hline 3 & 19 & 17.0 \\
\hline 4 & 04 & 3.6 \\
\hline 5 & 02 & 1.8 \\
\hline 6 & 01 & 0.9 \\
\hline Total & 112 & 100 \\
\hline
\end{tabular}

The mean age of the mothers in case group was 26.5 years (Table 1) and $41.1 \%$ were $2^{\text {nd }}$ gravida (Table 2). $42 \%$ cases delivered between 39 to 40 completed weeks compared to $36.6 \%$ in control group (Table 3). The median weight of the LGA babies was $3.7 \mathrm{kgs}$ (Table 4). There was a significantly higher number of post-dated pregnancies in the case group $(\mathrm{p}=0.04)$ (Table 5).
Table 3: Gestational age at delivery of case and control groups.

\begin{tabular}{|lllll|}
\hline Gestational age(weeks) & LGA & $\%$ & AGA & $\%$ \\
\hline $37-38$ & 7 & 6.3 & 25 & 22.3 \\
\hline $38-39$ & 31 & 27.7 & 31 & 27.7 \\
\hline $39-40$ & 47 & 42.0 & 41 & 36.6 \\
\hline $40-41$ & 27 & 24.1 & 15 & 13.4 \\
\hline Total & 112 & 100 & 112 & 100 \\
\hline
\end{tabular}

The existence of associated medical disorders like gestational diabetes mellitus, hypothyroidism and gestational hypertension in the case and control groups were $15.2 \%, 7.1 \%, 6.3 \%$ and $7.1 \%, 8.9 \%$ and $4.5 \%$ respectively. Significant statistical association was found with gestational diabetes mellitus $(\mathrm{p}=0.05)$ and LGA babies (Table 5).

Table 4: Birth weight of LGA babies.

\begin{tabular}{|c|c|c|c|c|c|}
\hline Obs. & Sum & Mean (kgs) & Variance & Std Dev $\quad$ (95\% CI mean) & Std Err \\
\hline 112 & 425.90 & 3.80 & 0.0531 & $3.76-3.85$ & 0.02 \\
\hline
\end{tabular}

Table 5: Comparison of maternal factors and outcome in LGA and AGA babies.

\begin{tabular}{|llllll|}
\hline Parameter & LGA $(\mathbf{n = 1 1 2})$ & AGA $(\mathbf{n = 1 1 2})$ & Chi $^{2}$ & & P value \\
\hline Multi gravida & 72 & 62 & 1.85 & 0.17 \\
\hline Post-dated gestation & 27 & 15 & 4.2 & 0.04 \\
\hline Gestational diabetes & 17 & 08 & 3.65 & 0.05 \\
\hline Hypothyroidism & 08 & 10 & 0.24 & 0.60 \\
\hline Gestational hypertension & 07 & 05 & 0.35 & 0.50 \\
\hline Primary LSCS & 41 & 26 & 4.8 & 0.02 \\
\hline
\end{tabular}


Regarding delivery outcomes, $61.2 \%$ cases required emergency Caesarean section and $29.4 \%$ babies needed neonatal intensive care in the case group.

The need for emergency Caesarean sections were significantly more in the case group when compared with the control $(\mathrm{p}=0.02)$ (Table 5). $2(1.8 \%)$ babies had shoulder dystocia in the study group.

\section{DISCUSSION}

Advanced maternal age was not found to be associated with LGA babies in a study by Khalil et al when the data was adjusted for potential confounding variables for pregnancy and maternal factors and similar results were obtained in the present study. ${ }^{5}$ In a Danish study by LanPidhainy et al, multiparous women were found to be at an increased risk for delivering LGA babies whereas the present study does not show such an association. ${ }^{6}$ Postdated pregnancies had an association with LGA babies in the present study $(\mathrm{p}=0.04)$.

Maternal overweight/obesity had a population attributing factor of $15.3 \%$ in case of LGA babies in a study in Amsterdam. ${ }^{7}$ Increasing gestational weight gain was shown to be associated with LGA babies and Caesarean section in the Danish study. ${ }^{6}$ Chung et al studied the adverse effects of increased gestational weight gain among 1950 pregnant women based on their prepregnancy body mass index and found that LGA infants and Caesarean deliveries were higher in that group. ${ }^{8}$ In their study by Mc Innis et al significant reduction of incidence of LGA babies were seen if the women achieved normal body weight pre pregnancy or lose $10 \%$ of their body weight. ${ }^{9}$ On the contrary Averett et al found no association of maternal obesity and LGA babies. ${ }^{10}$ However, since the present study was a retrospective analysis of hospital data, information regarding pre pregnancy body mass index and gestational weight gain was not available.

Brankica et al in their study showed a significant association of LGA babies with mothers having gestational diabetes mellitus and commented that fasting and $1^{\text {st }}$ hour plasma glucose levels from oral glucose tolerance test may predict LGA babies in pregnancies associated with this medical disorder. ${ }^{11}$ Abdalrahman et al have concluded from their study that gestational diabetes mellitus, even when controlled also can lead to higher number of LGA babies. ${ }^{12}$ In our current study also there was a significant association of LGA babies in pregnant women with gestational diabetes $(\mathrm{p}=0.05)$.

Clinical hypothyroidism was not found to be associated with LGA baby's $\mathrm{n}$ their studies by Kumru et al in Turkey and Nazarpour et al in Iran. ${ }^{13,14}$ Similar results were found in the present study also.

Regarding mode of delivery, both Lan-Pidhainy et al and Chung et al found an increased number of Caesarean sections in LGA babies. ${ }^{6,8}$ Person et al also inferred from their study that disproportionate LGA babies had a higher incidence of Caesarean sections and composite neonatal morbidities like birth trauma, low Apgar score, hypoglycemia and respiratory disorders. ${ }^{15}$ In this present study also there was a significant association of primary Caesarean section with LGA babies $(\mathrm{p}=0.02)$.

\section{CONCLUSION}

Maternal factors associated with large for gestational age babies were post-dated pregnancies and gestational diabetes mellitus. LGA babies were associated with more number of primary Caesarean sections.

\section{Funding: No funding sources}

Conflict of interest: None declared

Ethical approval: The study was approved by the Institutional Ethics Committee

\section{REFERENCES}

1. Orskou J, Kesmodel U, Henriksen TB. An increasing proportion of infants weigh more than 4000 grams at birth. Acta Obstet Gynecol Scand 2001;80:931-6.

2. Walsh JM, McAuliffe FM. Prediction and prevention of the macrosomic fetus. Eur J Obstet Gynecol Reprod Biol. 2012;162:125-30.

3. Boulet SL, Alexander GR, Salihu HM, Pass M. Macrosomic births in the united states: determinants, outcomes, and proposed grades of risk. Am J Obstet Gynecol. 2003;188(5):137-8.

4. Weissmann-Brenner A, Simchen MJ, Zilberberg E. Maternal and neonatal outcomes of large for gestational age pregnancies. Acta Obstet Gynecol Scand 2012;91:844-9.

5. Khalil A, Syngelaki A, Maiz N, ZInevich y, Nicolaides KH. Maternal age and adverse pregnancy outcomes-a cohort study. Ultrasound Obstet Gynecol. 2013;42(6):634-43.

6. Lan-Pidhainy $\mathrm{X}$, Nohr EA, Rasmussen KM. Comparison of gestational weight gain -related pregnancy outcomes in American primiparous and multiparous women. Am J Clin Nutr. 2013; 97(5):1100-6.

7. Djelantik AA, Kunst AE, van der Wal MF, Smit HA, Vrigkotte TG. Contribution of overweight and obesity to the occurrence of adverse pregnancy outcomes in a multi-ethnic cohort: population attributive factors for Amsterdam. BJOG. 2012;119 (3):283-90.

8. Chung JG, Taylor RS, Thompson JM, Anderson NH, Dekker GA, Kenny LC. Gestational weight gain and adverse pregnancy outcomes in a nulliparous cohort. Eur J Obstet Gynecol Reprod Biol. 2013; 167(2):149-53.

9. MacInnis N, Woolcott CJ, Mc Donald S, Kuhle S. Population attributable risk fractions of maternal overweight and obesity for adverse perinatal outcomes. Sci Rep. 2016;10(6):22895. 
10. Averett SL, Fletcher EK. Prepregnancy obesity and birth outcomes. Matern Child Health J. 2016; 20(3):655-64.

11. Brankica K, Valentina VN, Slagjana SK, Sasha JM. Maternal 75-g OGTT glucose levels as predictive factors for large-for-gestational age newborns in women with gestational diabetes mellitus. Arch Endocrinol Metab. 2016;60(1):36-41.

12. Almarzouki AA. Maternal and neonatal outcome of controlled gestational diabetes mellitus versus igh risk group without gestational diabetes mellitus: a comparative study. Med Glas (Zenica). 2013;10 (1):70-4.

13. Kumru P, Erdogdu E, Arisoy R, Demirci O, Ozkoral A, Ardic C. Effect of thyroid dysfunction and autoimmunity and pregnancy outcomes in low risk population. Arch Gynecol Obstet. 2015;291(5):104754.

14. Nazarpour S, Ramezani Teherani F, Simbar M, Azizi F. Thyroid dysfunctions and pregnancy outcomes. Iran J Reprod Med. 2015;13(7):387-96.

15. Persson M, Pasupathy D, Hanson U, Norman M. Disproportionate body composition and perinatal outcome in large-for-gestational-age infants to mothers with type 1 diabetes. BJOG. 2012;119(5):565-72.

Cite this article as: John LB, Reddi RP, Ghose S. Maternal factors associated with large for gestational age babies and its outcome when compared with those of appropriate for gestational age. Int J Reprod Contracept Obstet Gynecol 2017;6:3586-9. 